WWw.jmscr.igmpublication.org
Impact Factor 3.79

ISSN (e)-2347-176x

crossref DOI: _http://dx.doi.org/10.18535/jmscr/v3i9.48

Journal Of Medical Science And Clinical Research

\title{
Impact of Training Courses on Participant's Patient Centred Attitudes
}

\author{
Authors \\ Mudiyanse RM${ }^{1}$, de Silva $S^{2}$, Pallegama $\mathrm{R}^{3}$ \\ ${ }^{1}$ Department of Paediatrics, Faculty of Medicine University of Peradeniya, Sri Lanka \\ ${ }^{2}$ Lady Ridgeway Hospital, Colombo, Sri Lanka \\ ${ }^{3}$ Department of Basic sciences, Faculty of Dental sciences Unversity of Peradeniya Sri Lanka \\ Email: rasnayakamudiyanse@gmail.com
}

\begin{abstract}
Introduction - Patient centred attitudes are valuable attributes of doctors that should be preserved and enhanced during education programs. Curriculum related deterioration of attitudes has been recorded in literature. Relevant data on the impact of short-term training courses conducted in Sri Lanka is not available.

Objective - To compare and evaluate the impact of three different short-term training courses on the attitudinal changes of participants.

Methodology - All the participants of three workshops in advance life support (APLS), neonatal life support (NLS) and communication conducted in Anuradhapura in September 2012 were evaluated. Validated Sinhala version of the Patient Practitioner Orientation Scale (PPOS) was administered before and after training to assess the patient centeredness on Sharing and Caring sub-scales. Proportions showing improvements on total, sharing and caring scores were compared using Chi-square statistics across the three groups.

Results - Numbers of participants in APLS, NLS and Communication workshops were 25, 21 and 24 respectively. The response rates were $72 \%(18 / 25), 57 \%(12 / 21)$ and $75 \%(18 / 24)$. Improvement on the total PPOS was seen in 44\%(8/18), 42\% (5/12) and 72\%(13/18), while deterioration was seen in 56\%(10/18), $50 \%(6 / 12)$ and $28 \%(5 / 18)$ of APLS, NLS and Communication workshops participants. Improvement on the Sharing was seen in 50\%(9/18), 25\%(3/12) and 83\%(15/18) and improvement on the Caring was seen in $33 \%(6 / 18), 42 \%(5 / 18)$ and 56(10/18) of the participants in APLS, NLS and Communication workshops. Among the communication group the number of participants improved on Sharing was significant compared to the improvement observed in other two groups on the same aspect (Pearson Chi-Square=13.04, P=0.01).

Conclusions - Communication workshop enhances attitudes reemphasising its worth. Some Participants of APLS and NLS courses have deteriorated their attitudes more significantly on sharing domain calling for attention on the design of those training courses. Sustainability of this immediate impact on the attitudes needs further evaluation.
\end{abstract}

Keywords - attitudes, short term training courses, patient centeredness, advanced paediatric life support, Communication workshops, neonatal life support courses

\section{INTRODUCTION}

Goals of teaching and learning extend beyond acquisition of knowledge and skills to encompass change of attitudes, behaviour and developing relationships ${ }^{[1]}$. One should build understanding about self and the rest of the world in the process of learning. Teachers should be mindful about the impact of educational activities on students' attitudes and behaviour ${ }^{[2]}$. Teaching methods particularly paternalistic approaches, role modelling and the content itself can result in deterioration of humanistic attitudes. 
Patient centeredness is an attitude where doctors and patients come to a mutual understanding in managing health care problem by sharing information ${ }^{[3,4]}$. Patients would be treated as whole human been rather than a disease and provide care with respect and sharing information and making joint decisions in health care ${ }^{[4,5]}$. Patient centred care (PCC) as oppose to doctor centred or disease centred care has gain recognition due to its wellestablished multitudes of advantages to a wider spectrum of stakeholders of health care delivery in the society. PCC provide better patient satisfaction, treatment adherence, cost effectiveness, therapeutic out come, lesser conflicts and lawsuits and patient empowerment ${ }^{[6,7,8,9]}$.

Patient centeredness and empathy compliment each other and they are educable attitude. Curricular design, teaching methods, role modelling and hidden curriculum can greatly influence the patient centeredness ${ }^{[10]}$ as well as empathy ${ }^{[11,12]}$. Deterioration of humanistic attitudes of medical students has been well documented ${ }^{[10,13,14]}$. Such an adverse impact will not be evident, as attitudes are not measured as a routine practice. Therefore careful consideration of the impact of the curriculum on students' attitudes becomes a responsibility of curriculum designers.

Continues Professional Development (CPD) is an essential and integral part of any health care system to facilitate doctors updating the ever-expanding medical knowledge. In Sri Lanka the ministry of health as well as professional bodies conducts CPD activities. Sri Lanka College of Paediatricians (SLCP) is conducting regular CPD programs at provincial level that includes advanced paediatric life support (APLS), neonatal life support (NLS) and communication workshop. These programs are organized simultaneously for three deferent groups of people for cost effectiveness and logistic reasons. Main focus of three workshops differs from each other. However there impact on patient centred attitudes is likely and crucial. Therefore this study was designed to evaluate the impact of these CPD programs on their participants.

\section{METHODS}

All the participants of three workshops in advance life support (APLS), neonatal life support (NLS) and communication conducted in Anuradhapura in September 2012 were involved in the research. However completion of the PPOS questioner was not compulsory anonymity was maintained using a code number. Pre and post evaluation of patient centred attitudes was done using the validated Sinhala version of the Patient Practitioner Orientation Scale (PPOS). Proportions showing improvements on total, sharing and caring scores were compared using Chi-square statistics across the three groups.

Patient Practitioner Orientation Scale is a selfreporting instrument with 18-likart-scale items with a scale from totally agree (0) to totally disagree (6). Nine of the PPOS items measure the caring attitudes and 9 measure sharing attitudes. Some of the item are negatively worded and reversed scored.

\section{RESULTS}

Characteristics of the sample and the response rate are given in table one. Pre and post course PPOS values are given in the table two. Among the communication group the number of participants improved on Sharing was significant compared to the improvement observed in other two groups on the same aspect (Pearson Chi-Square=13.04, $\mathrm{P}=0.01$ ). Number of participants in APLS and NLS group has lower PPOS scores at the post-test is given in the table 3 . However this finding was not statistically significant.

\section{DISCUSSION}

Observations of this pre and post-test indicate that communication workshop group has significantly improved sharing attitudes of over other two CPD programs as expected. APLS and NLS participants showed statistically non-significant deterioration of their attitudes. Significance of this observation needs further evaluation. However the evidence seems reasonable enough to recommend regular monitoring these CPD courses for the impact of student's attitudes. 
CPD courses of the SLCP are conducted by a trained and experienced group of resource persons. Teaching programs are intensive but very much interactive. Students are tested on knowledge and skills at the end of the APLS and NLS courses. Communication workshop emphasises mainly on the relationships and communication. There is no formal assessment at the end of the course. Education methods, role modelling and content of a course can influence attitudes. The APLS and NLS work with manikins and focus mainly on recognition of the illness and initiating life saving procedures. Thereby communication and relationships are not highlighted. These could attribute as causes of possible deterioration of attitudes.

Paying attention to wider spectrum of outcomes of educational programs is vital in any field, but it is more so for the field of healthcare. Education should result in enhanced knowledge, skills, attitudes, behaviour and building relationships. In fact this could extend to understanding self and others. A conscious effort at the stage of curricular design can instilled these extended attributes also.

Student centred teaching as oppose to teacher cantered teaching cause less stress and results in students better equipped with logical thinking as well as good attitudes.

\section{LIMITATION OF THE STUDY}

This isolated observation in a single sample needs further evaluations to arrive at conclusions. Poor response rate resulted due to voluntary nature of the study has result in poor validity.

Conclusions

Communication workshop seems to have enhanced attitudes reemphasising its worth. Some Participants of APLS and NLS courses have deteriorated their attitudes more significantly on sharing domain calling for attention on the design of those training courses. Sustainability of this immediate impact on the attitudes needs further evaluation. These finding signify the need to pay attention to possible impact on attitude during CPD programs.
Table 1 - Description of respondents (\%) total and pre-test and post test respondents

\begin{tabular}{|l|c|c|c|}
\hline & Total & $\begin{array}{c}\text { Number of Pre-test } \\
\text { respondents }(\%)\end{array}$ & $\begin{array}{c}\text { Number of Post-test } \\
\text { respondents }(\%)\end{array}$ \\
\hline APLS & 25 & $25(100 \%)$ & $18(72 \%)$ \\
\hline NLS & 21 & $21(100 \%)$ & $12(57 \%)$ \\
\hline Communication & 24 & $24(100 \%)$ & $18(75 \%)$ \\
\hline
\end{tabular}

Table 2 - Average pre and post PPOS total, sharing and caring scores (SD)

\begin{tabular}{|c|c|c|c|c|c|c|}
\hline & \multicolumn{2}{|c|}{ Total PPOS score } & \multicolumn{2}{|c|}{$\begin{array}{ll}\begin{array}{l}\text { Sharing } \\
\text { score }\end{array} & \text { PPOS } \\
\end{array}$} & \multicolumn{2}{|c|}{$\begin{array}{ll}\begin{array}{l}\text { Caring } \\
\text { score }\end{array} & \text { PPOS } \\
\end{array}$} \\
\hline & Pre & Post & Pre & Post & Pre & Post \\
\hline APLS & $\begin{array}{l}4.58 \\
(0.63)\end{array}$ & $\begin{array}{l}4.64 \\
(0.53)\end{array}$ & $\begin{array}{l}4.33 \\
(0.83)\end{array}$ & $\begin{array}{l}4.42 \\
(0.52)\end{array}$ & $\begin{array}{l}4.84(0 . \\
58)\end{array}$ & $\begin{array}{l}4.86 \\
(0.63)\end{array}$ \\
\hline $\begin{array}{l}\text { Communic } \\
\text { ation }\end{array}$ & $\begin{array}{l}4.37 \\
(0.42)\end{array}$ & $\begin{array}{l}4.70 \\
(0.67)\end{array}$ & $\begin{array}{l}3.80 \\
(0.52)\end{array}$ & $\begin{array}{l}4.34 \\
(0.78)\end{array}$ & $\begin{array}{l}4.90 \\
(0.63)\end{array}$ & $\begin{array}{l}5.06 \\
(0.70)\end{array}$ \\
\hline NLS & $\begin{array}{l}4.50 \\
(0.47)\end{array}$ & $\begin{array}{l}4.29 \\
(0.48)\end{array}$ & $\begin{array}{l}4.04 \\
(0.74)\end{array}$ & $\begin{array}{l}3.84 \\
(0.60)\end{array}$ & $\begin{array}{l}4.95 \\
(0.47)\end{array}$ & $\begin{array}{l}4.73 \\
(0.57)\end{array}$ \\
\hline
\end{tabular}

Table 3 - Comparison of number $(\%)^{*}$ of participants who show improvement, deterioration or no change of PPOS scores according to CPD groups

\begin{tabular}{|l|l|l|l|l|}
\hline & & $\begin{array}{l}\text { APLS } \\
(18)\end{array}$ & NLS (12) & $\begin{array}{l}\text { Communicatio } \\
\mathrm{n}(18)\end{array}$ \\
\hline \multirow{4}{*}{ Total } & Improving & $8(44 \%)$ & $5(42 \%)$ & $13(72 \%)$ \\
\cline { 2 - 5 } & Deteriorating & $10(56 \%)$ & $6(50 \%)$ & $5(28 \%)$ \\
\cline { 2 - 5 } & Same & 0 & $1(8 \%)$ & 0 \\
\hline \multirow{4}{*}{ Sharing } & Improving & $9(50 \%)$ & $3(25 \%)$ & $15(83 \%)$ \\
\cline { 2 - 5 } & Deteriorating & $8(44 \%)$ & $7(58 \%)$ & $1(6 \%)$ \\
\cline { 2 - 5 } & Same & $1(6 \%)$ & $2(16 \%)$ & 0 \\
\hline \multirow{4}{*}{ Caring } & Improving & $6(33 \%)$ & $5(42 \%)$ & $10(56 \%)$ \\
\cline { 2 - 6 } & Deteriorating & $9(50 \%)$ & $6(50 \%)$ & $6(33 \%)$ \\
\cline { 2 - 5 } & Same & $1(6 \%)$ & $1(8 \%)$ & $1(6 \%)$ \\
\hline
\end{tabular}

*Percentages were calculated out of the total that completed the post-test

\section{REFERENCES}

1. Bullock I, Davis M, Lockey A, Jones KM. Packet Guide to teaching for Medical instructors. Second Edition. Pages 57- 67 BMJ Books, Blackwell Publishing

2. Haidet P. Patient-centredness and its challenge of prevailing professional norms . Med Educ. 2010;44:643-644.

3. Balint E. The possibilities of patientcentered medicine. 


\section{J.ROY.COLL.GEN.PRACTT. $\quad$ 1969;17:} 269-276.

4. Krupat E, Hiam CM, Fleming MZ, Freeman P. Patient-centeredness and its correlates among first year medical students. Int $\mathbf{J}$ Psychiatry Medicine. 1999;29: 347-356.

5. Engle GL. The Clinical Application of the Biopsychosocial Model.Amer J Psychiat. 1980;137:535-544.

6. Krupat E, Yeager CM, Putnam S. Patient Role Orientations, Doctor - Patient fit, and visit Satisfaction. Psychology and health. 2000;15:707-719.

7. Krupat E, Bell RA, KravitzRL,Thom D. When physicians and patients think alike: patient-centered beliefs and their impact on satisfaction and trust. Journal of Family Practice. 2001;50:1057-1062.

8. Little $\mathrm{P}$, Everitt $\mathrm{H}$, Williamson I, Observational study of effect of patient centredness and positive approach on outcomes of general practice consultations. BMJ. 2001;323:908-911.

9. Hirsh D, Gaufberg E, Ogur, Cohen P, Krupat E, Cox M, Pelletier S, Bor D, When physicians and patients think alike: patientcentered beliefs and their impact on satisfaction and trust, Academic Medicine. 2012; 87: 643-650.

10. Haidet P, Kelly A, Chau C, Characterizing the Patient-Centeredness of Hidden Curricula in Medical Schools: Development and Validation of a NewMeasure. Academic Medicine, Vol. 80, No. 1 / January 2005.

11. Hojat M, Joseph S. G., Thomas J.N., Salvatore M, Michael V., Mechael M., Physician Empathy: Definition, Components, Measurement, and Relationship to Gender and Specialty, Am J Psychiatry 2002; 159:1563-1569.

12. Hojat M. Empathy in Patient care. Antecedents, Development, Measurement, and outcomes.2007 Springer Science.

13. Tsimitiou Z, Kerasidou O, Efstathiou N, Papaharitou S, Hatzimouratidis K,
\&Hatzichristou D. Medical students' attitudes toward patient-centred care: a longitudinal survey. MEDICAL EDUCATION.2007; 41: 146-53.

14. Krupat E, Pelletier S, Alexander EK, Hirsh D, Ogur B, Schwartzstein R. Can Changes in the Principal Clinical Year Prevent the Erosion of Students' Patient-Centered Beliefs? . Academic Medicine. 2009; 85: 582-586. 